\title{
Decreased Expression of Inhibitor of DNA-binding (Id) Proteins and Vascular Endothelial Growth Factor and Increased Apoptosis in Ovarian Aging
}

\author{
Min Jung Park', Sea Hee Park', Sung Eun Moon², Ja Seong Koo', \\ Hwa Sook Moon ${ }^{2}$ and Bo Sun Joo ${ }^{1+}$ \\ ${ }^{1}$ Center for Reproductive Medicine, Good Moonhwa Hospital, Busan 601-803, Korea \\ ${ }^{2}$ Department of Obstetrics and Gynecology, Good Moonhwa Hospital, Busan 601-803, Korea
}

\begin{abstract}
This study examined the expression of inhibitor of DNA-binding (Id) proteins and vascular endothelial growth factor (VEGF) in the ovary according to female age using a mice model as the first step in investigating the potential role of Ids and VEGF in ovarian aging. C57BL inbred female mice of three age groups $(6-9,14-16$, and $23-26$ weeks) were injected with $5 \mathrm{IU}$ pregnant mare's serum gonadotropin (PMSG) in order to synchronize the estrus cycle. After $48 \mathrm{~h}$, ovarian expression of Ids and VEGF was analyzed by reverse transcriptase-polymerase chain reaction (RT-PCR), western blot and immunohistochemistry. Ovarian apoptosis was examined by ovarian expression of Bcl-2 and Bcl-xL. Expression of Id-1 and VEGF was decreased with advancing female age, but not Id-2, Id-3, and Id-4. In particular, their expressions were significantly decreased in aged mice of $23-26$ weeks compared with the young mice of $6-9$ weeks ( $p$ $<0.05)$. In contrast, ovarian apoptosis was greatly increased in the aged mice compared to the young mice. This result suggests that Id-1 may have an implicated role in ovarian aging by associating with VEGF.
\end{abstract}

Key words : Ovarian aging, Apoptosis, Id proteins, VEGF

\section{INTRODUCTION}

Inhibitor of DNA-binding (Id) proteins consist of four isoforms (Id-1, Id-2, Id-3, and Id-4) that lack a basic DNA-binding domain, form heterodimers and act as a negative regulator of helix-loop-helix transcription factors (Norton et al., 1998). Ids play an important role in cell proliferation, differentiation and senescence (Norton \& Atherton, 1998; Alani et al., 1999). It has been recently reported that Ids are expressed in steroidogenic cells of the ovary of ovine and avian (Johnson et al., 2008, 2009; Hogg et al., 2010). Upstream mediators of Id expression include members of the transforming growth factor-beta (TGF- $\beta$ ) superfamily including bone morphogenetic proteins (BMPs) (Korchynskyi \& ten Dijke, 2002), which are in-

\footnotetext{
${ }^{\dagger}$ Corresponding author: Bo Sun Joo, Center for Reproductive Medicine, Good Moonhwa Hospital, 899-8 Beomil 2-dong, Busan 601-803, Korea. Phone: +82-51-630-0748, Fax: +82-51-630-0750, E-mail: bosunjoo (a)hotmail.com
}

volved in many processes governing follicle development and oocyte maturation by differential regulation of steroidogenesis in granulosa cells (Shimasaki et al., 1999; Miyoshi et al., 2007). These results indicate that Ids may play a significant role in folliculogenesis via differential regulation by BMPs. However, little is known about the potential role of Ids in ovarian aging.

Ovarian aging resulting from advancing female age is an important factor contributing to an increasing incidence of infertility, but remains a difficult problem in infertility treatment. One of the main causes for age-related decline of fertility is associated with deterioration of oocyte quality, such as increased percentage of abnormal/degenerating oocytes (Tarin et al., 2001), chromosomal aneuploidy (te Velde \& Peasron, 2002) and the injury of mitochondrial DNA (Keefe et al., 1995; Thouas et al., 2005). However, a recent review suggested a possible mechanism that age-related decline of oocyte quality may occur as a result of inadequate ovarian angiogenesis in primordial follicles as well as ovarian 
stroma vessels (Tatone et al., 2008).

Ovarian angiogenesis plays an important role in a series of events of folliculogenesis such as follicular growth and the selection of dominant follicle (Geva \& jaffe, 2000). Vascular endothelial growth factor (VEGF) plays a critical role in angiogenesis. It has been known that the expression of VEGF is controlled by Id-1 (Ling et al., 2005; Kim et al., 2007; Maw et al., 2008). In this respect, Ids may be critical targets for the regulation of ovarian angiogenesis and folliculogenesis. Therefore, this study investigated the expression of Ids and VEGF in the ovary according to female age using a mice model as the first step in understanding the potential role of Ids and VEGF in ovarian aging.

\section{METHODS}

\section{Animals}

In all experiments, C57BL inbred female mice were used and they were purchased from the Korea Experimental Animal Center (Daegu, Korea). Mice were maintained on light-dark cycle, with light on at 5:00 AM and off at 7:00 PM, and with food and water available $a d$ libitum. This study was approved by the Institutional Review Board of Dong-A University Hospital.

\section{Superovulation and collection of ovaries}

Female mice of three age groups $(6-9,14-16$, and 23 - 26 weeks) were injected intraperitoneally with 5IU pregnant mare's serum gonadotropin (PMSG; Sigma, St Louis, MO, USA) in order to synchronize the estrus cycle. Forty-eight hours after injection of PMSG, the mice were sacrificed by cervical dislocation and ovaries were collected. Ovarian expression of Ids and VEGF was examined by reverse transcriptase-polymerase chain reaction (RT-PCR), western blot and immunohistochemistry. Ovarian apoptosis was examined by ovarian expression of anti-apoptotic members, Bcl-2 and Bcl-xL by RT-PCR. Ten mice per each age group were used in this study.

\section{RNA preparation and RT-PCR}

Total RNA were extracted using Trizol reagent (Invitrogen, Carlsbad, CA, USA) according to the manufacturer's protocol. Complementary DNA (cDNA) was synthesized from $5 \mu \mathrm{g}$ of total RNA with AMV Reverse Transcriptase (Promega, Madison, WI, USA) using a random hexamer (Bioneer, Daegu, Korea) at $42^{\circ} \mathrm{C}$ for $1 \mathrm{~h}$. Template cDNA was subjected to PCR amplification using gene-specific sense and antisense primers under the conditions shown in Table 1. PCR products were visualized by electrophoresis on $1.2 \%$ agarose gel. The PCR bands were quantified and normalized relative to the control band with Image $\mathrm{J}$ (version $1.35 \mathrm{~d}$, National Institutes of Health Image software, Bethesada, MO, USA).

\section{Western blot analysis}

Proteins were extracted by mechanical homogenization of ovaries in the presence of $200 \mu \mathrm{l}$ ice-cold lysis buffer (50 mM Tris- $\mathrm{HCl}$ (pH 7.5), $150 \mathrm{mM} \mathrm{NaCl}, 1 \%$ Nonidet P-40, 1 mM EDTA) containing protease inhibitor. The protein content of cell lysate was determined with Bradford reagent (Bio-Rad, Hercules, CA, USA) using bovine serum albumin (BSA) as the standard. We separated $60 \mu \mathrm{g}$ of cell lysate by SDS-PAGE and transferred to PVDF (immobilon-P) membrane (Millipore, Bedford, MD, USA). The transfer was performed at a constant voltage of $15 \mathrm{~V}$ for $90 \mathrm{~min}$. For western blotting, the membrane was incubated with anti-mouse VEGF rabbit IgG antibody (1:100; R\&D systems, Minneapolis, MN, USA), anti mouse Id-1 rabbit IgG antibody (1:200; Santa Cruz Biotech, Santa Cruz, CA, USA) and anti-mouse actin rabbit IgG antibody (1:5,000; Sigma) in tris-buffered saline (TBS) containing $1 \%$ tween 20 (TBS-T) supplemented with skim milk for $2 \mathrm{~h}$ at RT. After washing three times with TBS-T, the blotted membranes were incubated with horseradish peroxidase (HRP)conjugated goat antibody (Santa Cruz Biotech) for $30 \mathrm{~min}$ at RT. After washing three times with TBS-T, the proteins bands were visualized using enhanced chemiluminescence (ECL) detection system according to the recommended 
Table 1. Primers sequences used for PCR amplification and conditions

\begin{tabular}{|c|c|c|c|c|}
\hline Gene & Sequence & $\operatorname{Tm}\left({ }^{\circ} \mathrm{C}\right)$ & Cycles & Product size $(\mathrm{bp})$ \\
\hline \multirow{2}{*}{ Id-1 } & FW : CTGCTCTACGACATGAACGGC TG & \multirow{2}{*}{57} & \multirow{2}{*}{28} & \multirow{2}{*}{272} \\
\hline & RV : CGACACAAGATGCGATCGTC & & & \\
\hline \multirow{2}{*}{ Id-2 } & FW : AAAACAGCCTGTCGGACCAC & \multirow{2}{*}{58} & \multirow{2}{*}{38} & \multirow{2}{*}{314} \\
\hline & RV : AGTCGTAGGACAGGAACGTC & & & \\
\hline \multirow{2}{*}{ Id-3 } & FW : GCTTAGCCAGGTGGAAATCC & \multirow{2}{*}{56} & \multirow{2}{*}{42} & \multirow{2}{*}{138} \\
\hline & RV : ACAAGTTCCGGAGTGAGCTC & & & \\
\hline \multirow{2}{*}{ Id-4 } & FW : CTGTGCCTGCAGTGCGATAT & \multirow{2}{*}{57} & \multirow{2}{*}{28} & \multirow{2}{*}{134} \\
\hline & RV : AGCTGCAGGTCCAGGATGTA & & & \\
\hline \multirow{2}{*}{ VEGF } & FW : CTTGTTCAGAGCGGAGAA AGC & \multirow{2}{*}{57} & \multirow{2}{*}{28} & \multirow{2}{*}{125} \\
\hline & RW : ACATCTGCAAGTACGTTCGTT & & & \\
\hline \multirow{2}{*}{ Bcl-2 } & FW : AGCCGGGAGAACAGGGTATGATA & \multirow{2}{*}{58} & \multirow{2}{*}{35} & \multirow{2}{*}{473} \\
\hline & RW : TGTTGACGCTCTCCACACACA TG & & & \\
\hline \multirow{2}{*}{ Bcl-xL } & FW : AGGCAGGCGATGAGTTTGAAC & \multirow{2}{*}{59} & \multirow{2}{*}{35} & \multirow{2}{*}{399} \\
\hline & RW : GAACCACACCAGCCACAGTCA & & & \\
\hline \multirow{2}{*}{ GAPDH } & FW : ACCACAGTCCATGCCATCAC & \multirow{2}{*}{57} & \multirow{2}{*}{35} & \multirow{2}{*}{452} \\
\hline & RV : TCCACCACCCTGTTGCTGTA & & & \\
\hline
\end{tabular}

procedure (Amersham Pharmacia Biotech, Piscataway, NJ, USA). Actin expression was used as control. The protein bands for VEGF and Id-1 were quantified and normalized relative to the control band with Image $\mathrm{J}$ (National Institutes of Health Image software).

\section{Immunohistochemistry}

Serial sections $(4 \mu \mathrm{m})$ of formalin-fixed paraffin-embedded ovarian tissues were spread on the coated-slides, and placed in an oven at $60^{\circ} \mathrm{C}$ for $1 \mathrm{~h}$. And then the slides were deparaffinized in xylene and dehydrated in a graded series of ethanol. The endogeneous peroxidase was quenched with $0.3 \%$ hydrogen peroxide at RT for $10 \mathrm{~min}$ and then the tissues were rinsed three times for 10 min each time in PBS. The sections were incubated with normal serum, and then incubated with anti-mouse VEGF polyclonal rabbit IgG antibody (Lab Vision, Fremont, USA) and antimouse Id-1 rabbit IgG antibody (Santa Cruz Biotech) at a dilution of $1: 100$ in PBS/BSA overnight at $4{ }^{\circ} \mathrm{C}$. After three washing with PBS for 5 min each time, the samples were incubated with biotinylated conjugated secondary anti- body and HRT coupled to streptavidin conjugated antibody (Zymed, San Francisco, CA, USA) for $30 \mathrm{~min}$ at RT and washed three times. The sections were incubated with 3.3'-diaminibenzidine chromogen (DAB, Zymed). Counterstaining was performed with Mayer's hematoxylin (Sigma). The results were assessed by two pathologists under a light microscope.

6. Evaluation of ovarian apoptosis using the TUNEL assay

Serial sections $(4 \mu \mathrm{m})$ of formalin-fixed paraffin-embedded ovarian tissues collected from each age group were spread on the coated-slides, and placed in an oven at $60^{\circ} \mathrm{C}$ for $1 \mathrm{~h}$. And then the slides were deparaffinized in xylene and dehydrated in a graded series of ethanol.

\section{Statistical analysis}

Statistical analysis used SPSS program (version 12.0) and all data were presented as a mean \pm SEM. Comparison of the expression of Ids and VEGF according to female age was analyzed by one way ANOVA and student $t$-test. 
$P<0.05$ was considered to be statistically significant.

\section{RESULTS}

We investigated the mRNA expression profiles of ovarian Id-1, Id-2, Id-3, Id-4 and VEGF genes according to the female age by RT-PCR to understand whether the expressions of these factors decrease with advancing female age. As shown in Fig. 1, except for Id-4, the expressions of Id-1, Id-2, Id-3 and VEGF exhibited a tendency to decrease with advancing female age. Especially, the expression of Id-1 and VEGF in aged mice of 23-26 weeks significantly decreased compared to those in young mice of 6-9 weeks $(P<0.05)$ (Fig. 1).

Next, to examine whether these mRNA expression profiles show the same pattern in the protein level, we carried out western blot analysis for protein expressions of only Id-1 and VEGF because the mRNA expressions of these two factors resulted in a significantly decrease. As shown in RT-PCR experiment, both protein levels of Id-1 and VEGF in the ovary were also significantly decreased with
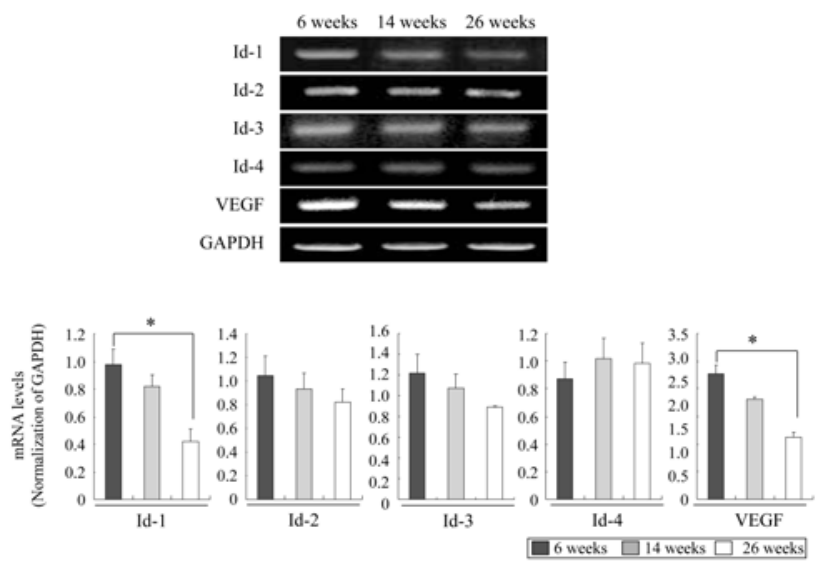

Fig. 1. Representative densitometry analysis of Ids (Id-1, Id-2, Id-3, Id-4) and VEGF mRNA expression in ovaries of different aged mice. Densitometry analysis of expressed Ids and VEGF content was performed using Image $\mathbf{J}$ (version $1.35 \mathrm{~d}$, NIH Image Soft) and normalized by GAPDH level. Data represent as mean \pm SEM. ${ }^{*} P<0.05$ (vs. 6-9 weeks group). advancing female age $(P<0.05)$. However, unlike mRNA expression results, the expression of Id-1 and VEGF at the protein level began to significantly decrease from the middle age group of 14-16 weeks old, and the levels of decrease were more obvious in $23-26$ weeks old (Fig. 2).

Immunohistochemistry was performed to evaluate the localized expression of Id-1 and VEGF in the ovary. Immunostaining of ovary sections also confirmed reduced expression of Id-1 and VEGF in older mice group of 23-26 weeks compared to the younger mice group of $6-9$ weeks. The Id-1 and VEGF expression was usually localized in granulosa cells, theca cells, stromal cells, and endothelial cells. In particular, the Id-1 antibody revealed more intense staining of granulosa cells and cumulus cells of younger mice group compared with older mice group (Fig. 3).

Ovarian apoptosis was also examined according to the age of female mice to confirm whether ovarian apoptosis increases with female aging and relates to the decreased expression of ovarian Id-1 and VEGF. As shown in Fig. 4 , the analysis of mRNA expression of two anti-apoptotic
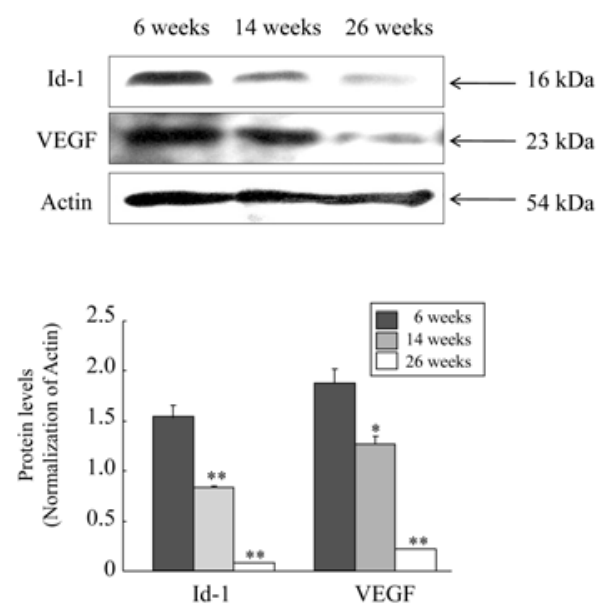

Fig. 2. Representative densitometry analysis of western blot for the expressions of Id-1 and VEGF in ovaries of different aged mice. Actin expression was used as control. Densitometry analysis of expressed Id-1 and VEGF content was performed using Image $\mathrm{J}$ program and normalized by the control level. Data are the mean \pm SEM. $* P<$ $0.05, * * P<0.005$ (vs. $6-9$ weeks group). 


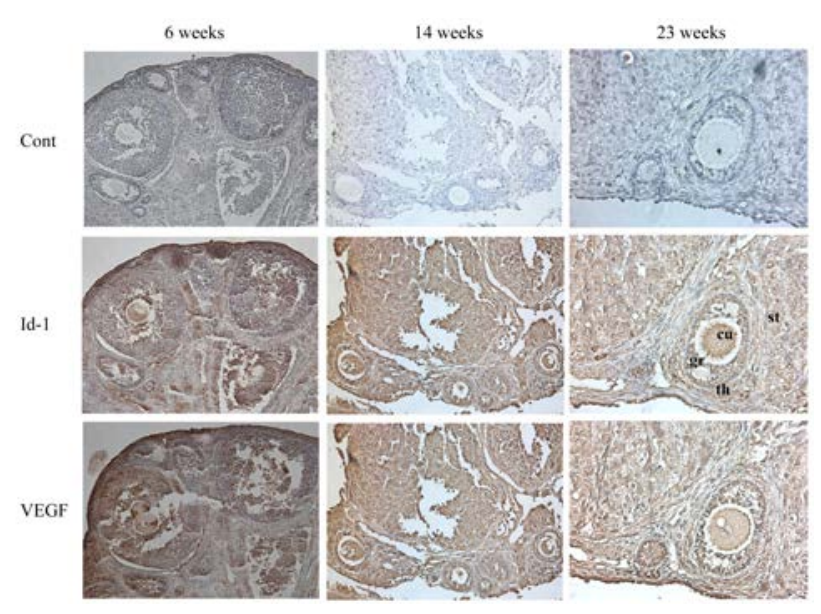

Fig. 3. Representative photomicrographs of immunostaining for Id-1 and VEGF in paraffin-embedded ovaries of different aged mice (magnification $\times 400)$. Control $(\mathrm{A}-\mathrm{C})$ : negative control, no primary antibody.

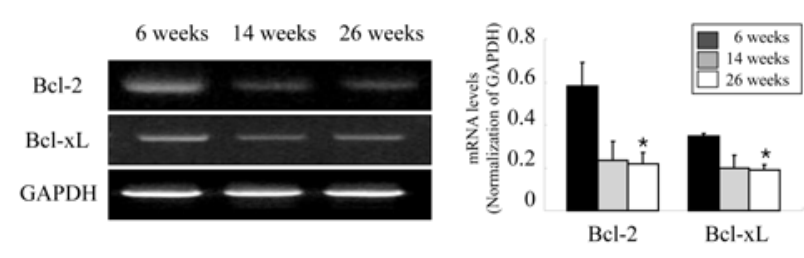

Fig. 4. Representative densitometry analysis of Bcl-2 and Bcl-xL mRNA expression in ovaries of different aged mice. Densitometry analysis of expressed Bcl-2 and Bcl-xL content was performed using Image $\mathrm{J}$ program and normalized by GAPDH level. Data represent as mean \pm SEM. $* P<0.05$ (vs. $6-9$ weeks group).

members in the ovary, Bcl-2 and Bcl-xL showed a significantly decrease in aged mice (23-26 weeks) compared to younger mice (6-9 weeks) (Fig. 4).

\section{DISCUSSION}

The present study showed that the expression of Id-1 was significantly decreased with advancing female age, suggesting a functional role of Id-1 in ovarian aging. To our knowledge, this is the first report to describe the expression of Id-1 during the follicular development in the mouse ovary according to female age.
The reason for decreased expression of Id-1 in the ovary of aged mice is as yet unclear. However, one can speculate two possible reasons. The first reason is the increased percentage of degenerative oocytes and atretic follicles with advancing age. It has been well known that the percentage of abnormal/degenerating oocytes increase with female age (Tarin et al., 2001). Id-1 was universally upregulated in the cumulus cells, but it was selectively downregulated in atretic follicles (Iijima et al., 2005). Our present study also showed increased ovarian apoptosis (Fig. 4) as well as decreased expression of Id-1 in cumulus cells (Fig. 2) with advancing age. Therefore, these results suggest that decreased Id-1 expression may be attributable to increased degenerative oocytes and atretic follicles resulting from ovarian aging.

However, it is a little bit risky to ascertain any relationship between the expression of Ids and VEGF and the expression of Bcl-2 and Bcl-xL from our present experiment. Moreover, the finding that ovarian apoptosis is increased with advancing age is hardly a novel one. It is known that VEGF is a strong survival factor for granulosa cell apoptosis (ovarian follicular atresia). We only suggest the possibility that ovarian expression of Id and VEGF may be associated with ovarian apoptosis by the finding that Id-1 and VEGF are both decreased in the aged mice. Therefore, further study on this topic is needed.

The second reason may be the reduced ovarian angiogenesis via decreased expression of VEGF with female aging. Id-1 plays a role in angiogenesis by regulating the expression of VEGF and Id-1 expression level correlates with microvessel counts (Kim et al., 2007; Maw et al., 2008). Indeed, our present study revealed a significantly decreased expression of VEGF as well as Id-1 in the ovary of aged mice. Many studies have shown that enhancing VEGF expression during the follicular phase may be useful in increasing ovarian angiogenesis and the number of predominant follicles destined for ovulation (Wulff et al., 2002; Danforth et al., 2003; Shimizu et al., 2003; Iijima et al., 2005). Our previous studies also demonstrated the importance of an 
adequate expression of ovarian VEGF in the production of good oocyte quality in aged female by showing that administration of pro-angiogenic factors such as sodium nitroprusside (SNP), leptin, and estrogen during superovulation in aged female mice increased not only in the number and quality of ovulated oocytes, but also in the expression of ovarian VEGF (Lee et al., 2008; Ha et al., 2010; Joo et al., 2010). These results suggest the possibility that the decreased expression of Id-1 in the ovary with female aging may affect the age-related fertility outcomes via the regulation of VEGF expression.

In the present study, Id-1 was expressed in granulosa cells, cumulus cells, stroma cells, theca cells, and endothelial cells. In particular, intense staining for Id-1 was observed in cumulus cells and granulosa cells of younger mice compared with older mice. Considering that Id-1 protein can induce cell proliferation and increase DNA synthesis (Norton and Atherton, 1998; Alan et al., 1999), this result suggests that decreased expression of Id-1 with aging may affect ovarian cell proliferation, such as granulosa cells and cumulus cells, and subsequently follicular development and oocyte quality.

It has been well reported that the expression of VEGF is detected in the granulosa cells, cumulus cells and stromal cells of ovary tissues as well as endothelial cells (Kaczmarek et al., 2005; Fraser, 2006). This result was also found in the images of immunohistochemistry of the present study, which showed that the expression of Id-1 and VEGF were detected in granulosa cells, theca cells, stromal cells, and endothelial cells.

One of bias arising from the present study is that the age difference of two or three weeks in each age group may result in individual difference within each age group. The sexual maturity and lifespan in the laboratory for mice is around 6 weeks and 1 year, respectively. Considering this reproductive physiology of mice, 6 to 9 weeks, 14 to 16 weeks, and 25 to 27 weeks in mice may be comparable with human teenage years, early 20-30 years of age, and late $30-40$ years of age in humans, respectively. Our pre- liminary study examined the difference of result according to the age and confirmed no significant difference between individuals in each age group. In this respect, we divided the ages into three groups and we think that the age difference of 2-3 weeks in each group does not affect the results between individuals in each group.

In conclusion, our present study showed decreased Id-1 and VEGF expression with increased ovarian apoptosis with advancing female age. This result suggests that Id-1 may play a functional role in follicular development and ovarian aging by associating with VEGF. This research may contribute to the development of a novel treatment strategy for the improvement of age-related decline of fertility. However, direct treatment of pro-angiogenic factor such as VEGF during superovulation for the activation of ovarian angiogenesis has a risk of possible side effects including ovarian hyperstimulation syndrome or tumor. In this respect, the controlled expression of VEGF via the regulation of Id-1 expression may prevent this risk. Therefore, the activation of ovarian angiogenesis via the regulation of Id-1 expression may be a promising and important future target for the development of new strategy for the treatment of age-related infertility.

\section{REFERENCES}

Alani RM, Hasskarl J, Grace M, Hernandez MC, Israel MA, Munger K (1999) Immortalization of primary human keratinocytes by the helix-loop-helix protein, Id-1. Proc Natl Acad USA 96:9637-9641.

Danforth DR, Arbogast LK, Ghosh S, Dickerman A, Rofagha R, Friedman CI (2003) Vascular endothelial growth factor stimulates preantral follicle growth in the rat ovary. Biol Reprod 68:1736-1741.

Fraser HM (2006) Regulation of the ovarian follicular vasculature. Reprod Biol Endocrinol 4:18-26.

Geva E, Jaffe RB (2000) Role of vascular endothelial growth factor in ovarian physiology and pathology. Fertil Steril 74:429-438. 
Ha CS, Joo BS, Kim SC, Joo JK, Kim HG, Lee KS (2010) Estrogen administration during superovulation increases oocyte quality and expressions of vascular endothelial growth factor and nitric oxide synthase in the ovary. J Obstet Gynaecol Res 36:789-795.

Hogg K, Etherington SL, Young JM, McNeilly AS, Duncan WC (2010) Inhibitor of differentiation (Id) genes are expressed in the steroidogenic cells of the ovine ovary and are differentially regulated by members of the transforming growth factor-beta family. Endocrinology 151:1247-1256.

Iijima K, Jiang JY, Shimazu T, Sasada H, Sato E (2005) Acceleration of follicular development by administration of vascular endothelial growth factor in cycling female rats. J Reprod Dev 51:161-168.

Johnson AL, Haugen MJ, Woods DC (2008) Role for inhibitor of differentiation/ deoxyribonucleic acid-binding (Id) proteins in granulosa cell differentiation. Endocrinology 149:3187-3195.

Johnson AL, Woods DC (2009) Dynamics of avian ovarian follicle development: cellular mechanisms of granulosa cell differentiation. General and Comparative Endocrinology 163:12-17.

Joo JK, Joo BS, Kim SC, Choi JR, Park SH, Lee KS (2010) Role of leptin in improvement of oocyte quality by regulation of ovarian angiogenesis. Anim Reprod Sci 119:329-334.

Kaczmarek MM, Schams D, Ziecik AJ (2005) Role of vascular endothelial growth factor in ovarian physiologyan overview. Reprod Biol 5:111-136.

Keefe DL, Niven-Fairchild T, Powell S, Buradagunta S (1995) Mitochondrial deoxyribonucleic acid deletions in oocytes and reproductive aging in women. Fertil Steril 64:577-583.

Kim HJ, Chung H, Yoo YG, Kim H, Lee JY, Lee MO, Kong G (2007) Inhibitor of DNA binding 1 activates vascular endothelial growth factor through enhancing the stability and activity of hypoxia-inducible factor1alpha. Mol Cancer Res 5:321-329.
Korchynskyi O, ten Dijke P (2002) Identification and functional characterization of distinct critically important bone morphogenetic protein-specific response elements in the Id1 promoter. J Biol Chem 277:4883-4891.

Lee DH, Joo BS, Suh DS, Park JH, Choi YM, Lee KS (2008) Sodium nitroprusside treatment during the superovulation process improves ovarian response and ovarian expression of vascular endothelial growth factor in aged female mice. Fertil Steril 89(Suppl):1514-1521.

Ling MT, Lau TC, Zhou C, Chua CW, Kwok WK, Wang Q, Wang X, Wong YC (2005) Overexpression of Id-1 in prostate cancer cells promotes angiogenesis through the activation of vascular endothelial growth factor (VEGF). Carcinogenesis 26:1668-1676.

Maw MK, Fujimoto J, Tamaya T (2008) Expression of the inhibitor of DNA-binding (ID)-1 protein as an angiogenic mediator in tumor advancement of uterine cervical cancers. Br J Cancer 99:1557-1563.

Miyoshi T, Otsuka F, Inagaki K, Otani H, TakedaM, Suzuki J, Goto J, Ogura T, Makino H (2007) Differential regulation of steroidogenesis by bone morphogenetic proteins in granulosa cells: involvement of extracellularly regulated kinase signaling and oocyte actions in folliclestimulating hormone-induced estrogen production. Endocrinology 148:337-345.

Norton JD, Atherton GT (1998) Coupling of cell growth control and apoptosis functions of Id proteins. Mol Cell Biol 18:2371-2381.

Norton JD, Deed RW, Craggs G, Sablitzky F (1998) Id helix-loop-helix proteins in cell growth and differentiation. Trends Cell Biol 8:58-65.

Shimasaki S, Zachow RJ, Li D, Kim H, Iemura S, Ueno N, Sampath K, Chang RJ, Erickson GF (1999) A functional bone morphogenetic protein system in the ovary. Proc Natl Acad Sci USA 96:7282-7287.

Shimizu T, Jiang JY, Iijima K, Miyabayashi K, Ogawa Y, Sasada H, Sato E (2003) Induction of follicular development by direct single injection of vascular endothelial growth factor gene fragments into the ovary of miniature 
glits. Biol Reprod 69:1388-1393.

Tarin JJ, Perez-Albala S, Cano A (2001) Cellular and morphological traits of oocytes retrieved from aging mice after exogenous ovarian stimulation. Biol Reprod 65:141-150.

Tatone C, Amicarelli F, Carbone MC, Monteleone P, Caserta D, Marci R, Artini PG, Piomboni P, Focarelli $\mathrm{R}$ (2008) Cellular and molecular aspects of ovarian follicle ageing. Hum Reprod Update 14:131-142.

te Velde ER, Peasron PL (2002) The variability of female reproductive aging. Hum Reprod Update 8:141-154. female age on mouse oocyte developmental competence following mitochondrial injury. Biol Reprod 73:366373.

Wulff C, Wilson H, Wiegand SJ, Rudge JS, Fraser HM (2002) Prevention of thecal angiogenesis, antral follicular growth, and ovulation in primate by treatment with vascular endothelial growth factor trap R1R2. Endocrinology 43:2797-2807.

(Received 18 January 2013, Received in revised form 7 February 2013, Accepted 5 March 2013)

Thouas GA, Trounson AO, Jones GM (2005) Effect of 